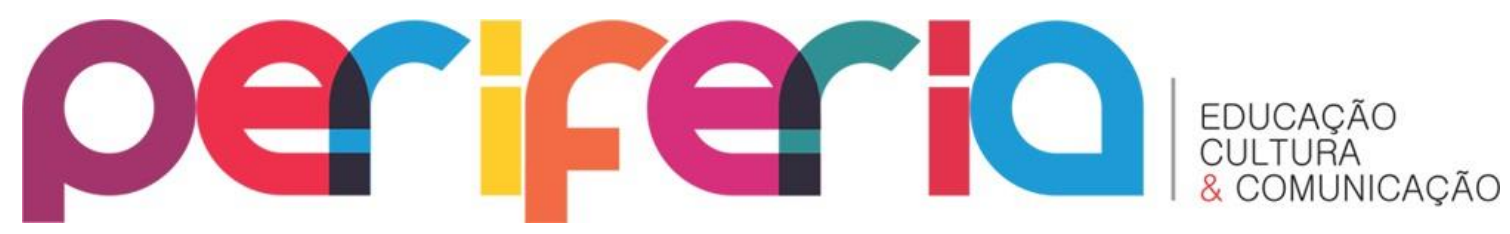

\title{
EDUCAÇÃO ESCOLAR INDÍGENA DIFERENCIADA E INTERCULTURAL ENTRE OS GUARANI MBYÁ DO RIO DE JANEIRO: O LEGITIMO E O REAL ${ }^{1}$
}

\author{
Katia Antunes Zephiro² \\ Universidade Federal Rural do Rio de Janeiro \\ Norielem de Jesus Martins ${ }^{3}$ \\ Universidade Federal Rural do Rio de Janeiro
}

\section{RESUMO}

Este artigo aborda o processo de construção da educação escolar diferenciada indígena no Rio de Janeiro na atualidade. A partir de um breve histórico dessa construção apontamos as principais demandas de educação escolar nas comunidades indígenas Guarani Mbyá no Estado, buscando compreender quem são estes sujeitos, de onde falam, a forma com que se relacionam e pensam a organização do tempo escolar a partir de sua própria concepção de educação. Discutiremos de que forma a interculturalidade pode se fazer presente na construção de um currículo decolonial, que valorize diferentes saberes em sua concepção. Neste intuito, consideramos essencial uma análise da vulnerabilidade social dessas comunidades para que as ações educativas sejam planejadas para fortalecimento intracultural, proporcionando assim a construção de bases para um interculturalismo crítico. Para discutir essa temática dialogaremos com autores do campo da Modernidade, Colonialidade e do interculturalismo crítico, de forma que possamos refletir sobre o atendimento realizado nas comunidades guarani e as necessidades existentes. Consideramos necessário garantir que os conhecimentos Guarani Mbya sejam os condutores do processo educativo e que sejam reconhecidos como saberes/conhecimentos válidos. Compreendemos que fortalecendo as relações intraculturais, ou seja, valorizando e estimulando a temporalidade guarani, pesquisas e vivências entre as comunidades, podemos minimizar os impactos da vulnerabilidade social empoderando esses sujeitos para um diálogo intercultural igualitário, na perspectiva de uma educação libertadora. Por fim faremos uma análise de como ao longo do tempo percebemos avanços e recuos na construção de um projeto público de educação escolar indígena diferenciada, específica, intercultural e bilíngue no Rio de Janeiro, refletindo sobre novas perspectivas para que possamos de fato atender aos anseios e demandas das comunidades Guarani Mbya. A partir das reflexões apresentadas nesse artigo

\footnotetext{
${ }^{1}$ Este artigo é fruto dos estudos realizados pelas autoras no âmbito do Programa de Pós-Graduação em Educação, Contextos Contemporâneos e demandas Populares da UFRRJ.

2 Historiadora, graduada pela Universidade do Estado do Rio de Janeiro e Mestranda pela UFRRJ, Programa de Pós-Graduação em Educação, Contextos Contemporâneos e Demandas Populares, Membro do grupo de Estudos e Pesquisas GPMC. E-mail: katiazephiro@yahoo.com.br.

${ }^{3}$ Pedagoga, graduada pela Universidade Federal Fluminense e Mestranda pela UFRRJ, Programa de PósGraduação em Educação, Contextos Contemporâneos e Demandas Populares. Membro do Grupo de Estudos e Pesquisas GPMC. E-mail: norielem pedagogia@hotmail.com
} 


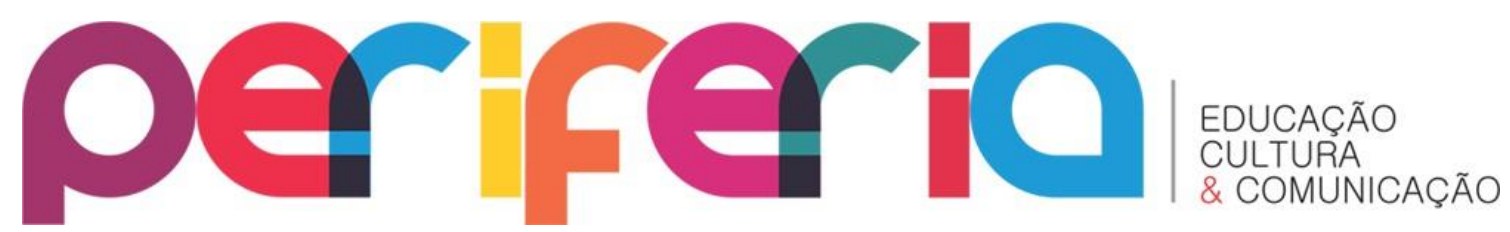

esperamos também evidenciar lutas históricas dessas comunidades no Litoral Sul Fluminense, estimulando a participação autônoma desses sujeitos na autoria de suas trajetórias individuais e coletivas.

Palavras-chave: Educação Escolar Indígena, Decolonialidade, Educação Guarani Mbyá, Interculturalismo Crítico.

\section{INDIGENOUS EDUCATION SCHOOL DIFFERENTIATED AND INTERCULTURAL AMONG THE GUARANI MBYA RIO DE JANEIRO: THE LEGITIMATE AND REAL}

\section{ABSTRACT}

This article discusses the process of construction of the indigenous differentiated education in Rio de Janeiro in the present time. From a brief history of this construction, we pointed the main demands of education in indigenous communities Guarani Mbyá in this State, trying to understand who are these people, where they speak, the way they relate and think the organization of school time from their own conception of education. We will discuss how interculturalism can be present in the construction of a colonialist curriculum that enriches different knowledge in their design. In that aim, we consider essential a social vulnerability analysis of these communities so that educational activities can be planned for intracultural building, providing the basis for a construction of a critical interculturalism. To discuss this theme we will dialogue with authors in the field of Modernity, Coloniality and critical interculturalism, so that we can reflect on the attention given in Guarani communities and existing needs. We consider necessary to ensure that the Guarani Mbya knowledge are the conductors of the educational process and to be recognized as a valid knowledge/expertise. We understand that strengthening intracultural relations, in other words, valuing and stimulating Guarani temporality, research and experiences between communities, we can minimize the impact of social vulnerability empowering these individuals to an egalitarian intercultural dialogue, in a perspective of a liberating education. Finally we will look at how over time we realized advances and setbacks in the construction of a public project of differentiated indigenous education, specific, intercultural and bilingual in Rio de Janeiro, reflecting on new perspectives in order that we can actually meet the needs and demands of the Guarani Mbya communities. From the ideas presented in this article we also hope to highlight historical struggles of these communities in the South Coast Fluminense, stimulating autonomous participation of these individuals in the authorship of their individual and collective trajectories.

Keywords: Indigenous Education, Decoloniality, Education Guarani Mbyá, Interculturalism critic. 


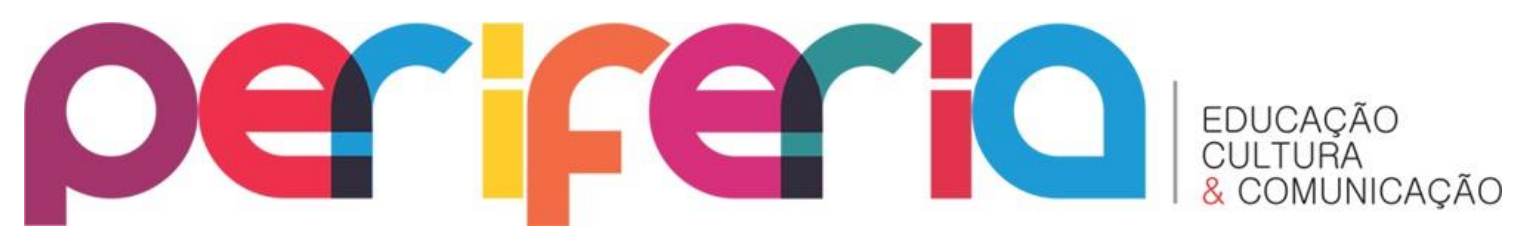

\section{INTRODUÇÃO: COMPREENDENDO O MODO DE ORGANIZAÇÃO GUARANI MBYÁ}

Este trabalho é fruto de pesquisa sobre educação escolar indígena junto ao grupo Guarani Mbya do Litoral Sul Fluminense a partir de nossa vivência em comum no projeto de escolarização EJA Guarani ${ }^{4}$. Embora este artigo não aborde especificamente esse projeto, as reflexões aqui presentes foram feitas a partir deste campo de estudos, ampliado por nossas vivências individuais. Para que possamos compreender melhor esse processo, consideramos essencial trazer à tona uma breve síntese da forma de organização desses povos no Litoral Sul e, mais recentemente, no Litoral Norte do Estado do Rio de Janeiro.

Clastres (1978), em seus estudos sobre os guarani mbyá no do Sul do País, observou que a cultura Mbyá parecia estar fundamentada na religiosidade e na busca pela terra sem mal. Para o autor, a terra sem mal seria um bom lugar para se viver, ao contrário da terra má, considerada um lugar ruim para viver. Porém, em análises mais recentes, percebemos que o conceito da "terra sem mal" esteve durante muito tempo impregnado de uma etnografia construída sob um olhar messiânico jesuítico, tendo em vista que em estudos mais recentes, como o de Pissolato (2006), e em demais pesquisas apontadas por ela sobre a religiosidade Guarani Mbyá, a mobilidademovimentação dos grupos guarani não está associada apenas a uma questão míticoreligiosa:

Esta afirmação de uma "cultura guarani" através do enfoque da mobilidade mbya aparece como um marco na bibliografia das últimas décadas. Sempre vinculado ao mito, o ethos religioso-migrante, nos trabalhos mais recentes, tende a receber um tratamento ampliado. Não é mais ou apenas o mito da terra sem mal que faz com que se caminhe, como já foi observado, mas um ethos caminhante que estaria dado desde o início, pelos criadores dos humanos (Guarani) na Terra, que os orientaria a caminhar e reproduzir um "verdadeiro" modo de vida. Este compreende a prática de cultivar e "espalhar" sementes, um modo apropriado de convivência e uma "espiritualidade guarani", aspectos que aparecem, em conjunto ou não, desenvolvidos nos trabalhos de Chamorro

\footnotetext{
4 Projeto de Escolarização realizado pela Secretaria Municipal de Educação, Ciência e Tecnologia de Angra dos Reis. 3a turma, no período de 2012 a 2014.
} 


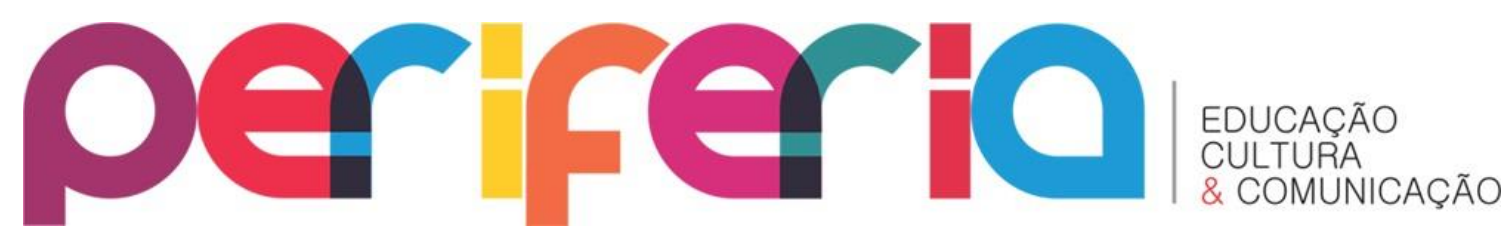

(1995 e 1998), Garlet (1997), Ladeira (1992, 2001), Ciccarone (2001), Mello (2001), entre outros. (PISSOLATO, 2006, p.88).

De acordo com dados do Instituto sócio ambiental ${ }^{5}$ (ISA), estima-se que a população guarani seja de 57.923 pessoas no Brasil, habitando os estados do MS, SP, PR, RS, RJ, ES, PA, SC, TO e também em países como Paraguai (41.200 pessoas), Argentina (6.500), e Bolívia (78.359). No Brasil, a população guarani está dividida em três subgrupos: Mbyá, Kaiowá, Nhãndeva. Atualmente, existem sete aldeias no Rio de Janeiro, conforme podemos visualizar na tabela abaixo:

Aldeias indígenas guarani no rio de janeiro em 2015

\begin{tabular}{|l|l|l|l|l|}
\hline \multicolumn{1}{|c|}{ Aldeia } & Localização & Habitantes & \multicolumn{1}{|c|}{$\begin{array}{c}\text { Situação } \\
\text { Territorial }\end{array}$} & Atividade Escolar \\
\hline Sapukai & Angra dos Reis & $* 379$ & Homologada & Sim \\
\hline Itaxi & Parati & $* 171$ & Homologada & Sim \\
\hline Araponga & Parati & $* 40$ & Homologada & Sim \\
\hline Rio Pequeno & Parati & $* *$ & Em Identificação & Sim \\
\hline $\begin{array}{l}\text { Arandu Mirim (Saco } \\
\text { do Marati }\end{array}$ & $* 28$ & Em Identificação & $?$ \\
\hline $\begin{array}{l}\text { Tekoa Ka'aguy Hovy } \\
\text { Porã }\end{array}$ & Maricá & $* * * 40$ & $\begin{array}{l}\text { Buscando } \\
\text { Reconhecimento }\end{array}$ & Sim \\
\hline Aldeia de Itaipuaçu & Maricá & $* * * 28$ & $\begin{array}{l}\text { Buscando } \\
\text { Reconhecimento }\end{array}$ & Sim \\
\hline
\end{tabular}

* Segundo dados do ISA (Instituto Sócio Ambiental - http://pib.socioambiental.org/pt)

** Segundo informação oral dos moradores da comunidade em Etapa Local de Conferência Indigenista 2015

*** Segundo dados da Prefeitura Municipal de Maricá 2015 http://www.marica.ri.gov.br/?s=print\&n=5045

Ressaltamos que, nestas comunidades, as relações entre as pessoas e grupos de parentesco estão em constante movimento, conforme exemplifica Pissolato com o conceito de mobilidade ${ }^{6}$ entre esses povos:

\footnotetext{
5 Instituto Sócio Ambiental 2015 (http://pib.socioambiental.org/pt/povo/guarani-mbya)

6 Ver mais sobre o conceito de "mobilidade" em PISSOLATO, Elizabeth de Paula. A Duração da Pessoa: mobilidade, parentesco e xamanismo mbya (guarani). Rio de Janeiro: UFRJ/MN/PPGAS, 2006.
} 


\section{periferio}

A história de cada pessoa adulta, homem ou mulher mbya que vive atualmente nas aldeias no litoral sudeste brasileiro, e também em outras que se espalham pelos estados do sul do país, pode ser descrita como uma sucessão de residências por locais diversos de ocupação Mbya, dos quais guarda uma impressão e, tanto quanto possível, a informação sobre o mapa da ocupação desde que tenha deixado o lugar, especialmente quando há relações de parentesco vinculando o indivíduo em questão a tais localidades. (PISSOLATO, 2006, p.105)

Desta forma, para iniciar o diálogo sobre o que seria a educação diferenciada guarani Mbyá, é preciso compreender as relações entre os diferentes tempos e espaços pelos quais os processos educativos se constituem dentro e fora destas comunidades. Com isso, ressalta-se que a educação escolar não deverá ser a responsável por reproduzir esses espaços tradicionais do conhecimento, mas poderá potencializá-los.

Segundo a fala recorrente das lideranças das aldeias do Litoral Sul Fluminense que pudemos registrar em nossos diários de campo por mais de uma ocasião, em uma aldeia Guarani Mbyá, a casa de reza (Opy) se constitui como local muito importante, pois é dentro desse espaço que os guaranis transmitem os conhecimentos tradicionais de sua cultura. É lá também onde ocorrem as cerimônias religiosas e rituais da comunidade, como o batismo e a consagração do milho, para que haja um bom plantio e uma boa colheita.

Outra relação importante para os Mbyá que temos observado, nas diferentes aldeias que visitamos durante a trajetória no Projeto EJA Guarani, é a relação que essas comunidades mantêm com os mais velhos. A fala e a opinião dos xeramoi (anciãos, avós) são respeitadas e estimuladas dentro da comunidade, o que demonstra uma relação diferenciada com a aprendizagem.

Em nossa atuação no projeto EJA Guarani, partilhamos do cotidiano de vinte e cinco jovens/ adultos, que tinham no artesanato e nos projetos desenvolvidos na aldeia a sua principal fonte de renda. Algumas famílias extensas sobrevivem da renda dos profissionais indígenas contratados pela escola e posto de saúde, onde as vagas, 


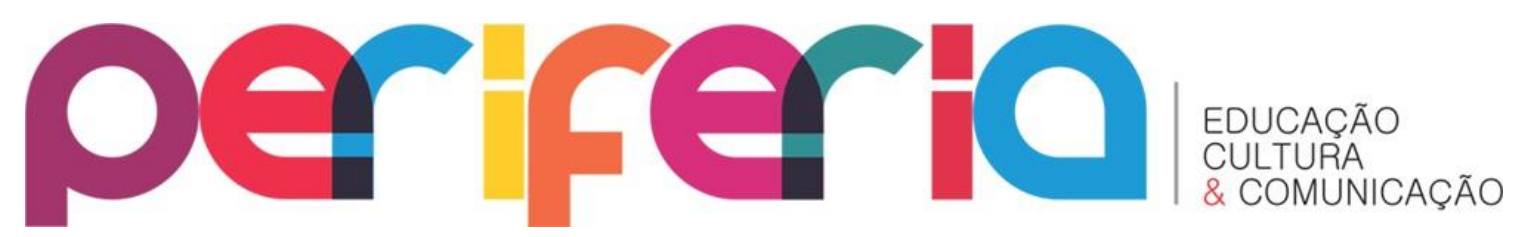

geralmente, estão distribuídas por esses grupos familiares (joapyguá). As crianças aprendem a acompanhar o caminho da família através destes diferentes espaços educativos na aldeia, das histórias, do trabalho, da música, da dança, das brincadeiras e, mais recentemente, da internet e da televisão.

Durante o Seminário "Juruá Escuta", realizado pela Secretaria Municipal de Assistência Social e Direitos Humanos de Angra dos Reis, foram compartilhadas estatísticas alarmantes sobre a mortalidade infantil nas aldeias, considerada elevada em relação ao que se considera previsível. Outro fator exposto foi o da renda per capta de cada núcleo familiar, que, segundo os dados apresentados, girava em torno de 77 reais mensais, por família, o que pode demonstrar um estado de vulnerabilidade social dessa comunidade. Consequentemente, quando a fome sobressai sobre a cultura, os guarani são obrigados a procurar subempregos na comunidade local, o que quase sempre é um fracasso, pois sabemos como é tensa a relação entre povos indígenas e sociedade envolvente. Com os guarani em Angra dos Reis não é diferente. . É na busca por soluções e pela sobrevivência que as lutas acontecem, inclusive por uma escola diferenciada e pela manutenção da cultura.

\section{INTERCULTURALIDADE E EDUCAÇÃO ESCOLAR INDÍGENA DIFERENCIADA: ENTRE 0 LEGÍTIMO E O REAL}

Defender a escola no universo indígena impõe negar concepções pedagógicas que veem a escola como estrutura rígida, tornando-a sensível a uma nova formatação" (BARROS e LIMA, 2002, p.116).

Segundo Barros (2001) desde a década de 80 ocorrem experiências educacionais dirigidas ao ensino fundamental e a formação de professores nas escolas de Sapukai, em Angra dos Reis, e também em Itaxi e de Araponga, em Parati, a partir da confluência de ações de diversas instituições governamentais e não governamentais. No início dos anos 90 , o projeto de uma escola indígena diferenciada

\footnotetext{
7 Seminário realizado em agosto de 2014, pela Secretaria de Ação Social e Direitos Humanos de Angra dos Reis, onde estiveram presentes as lideranças guarani e pataxó de Angra dos Reis.
} 


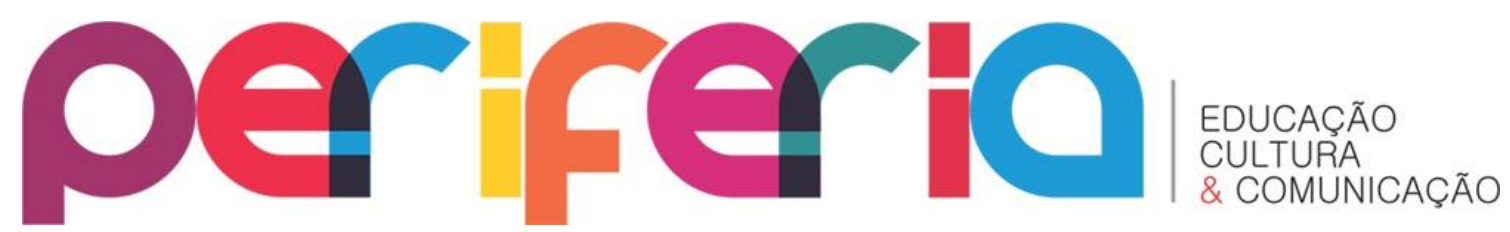

nas comunidades do Rio de Janeiro começa a se fortalecer, juntamente com o movimento indígena a nível nacional, propondo uma escola aberta a contatos interculturais, porém com aprendizado em língua materna e com professores indígenas. Surge, então, a preocupação com a formação deste novo profissional, e a escola indígena começa a se ressignificar, a partir da atuação dos profissionais das próprias comunidades.

No Rio de Janeiro, entre o período de 1999 a 2003, as discussões sobre educação nas aldeias Guarani aconteciam com o apoio do CIMI (Conselho Indigenista Missionário), do CEDAC (Centro de Ação Comunitária), das Secretarias Municipais de Educação de Angra dos Reis e Parati e também de iniciativas diferenciadas, como o projeto de extensão ${ }^{8}$ do Professor Armando Martins de Barros, no âmbito do Laboratório de Estudos da Imagem e do Olhar (LEIO) - Universidade Federal Fluminense (UFF). Neste mesmo período, em 1999, instituiu-se o Núcleo de Educação Indígena do Rio de Janeiro (NEI-RJ), a partir da união dos indígenas com diferentes pesquisadores na área de Educação Indígena. Nobre relata, a partir das memórias do NEI-RJ, a definição de ação e objetivos do Núcleo:

Definição: Fórum interinstitucional estadual de diferentes agentes que atuam na área de educação indígena no Estado do Rio de Janeiro. Objetivo: Potencializar as ações de assessoria em educação indígena; promover ações cooperativas e coordenadas com mesmos objetivos; evitar superposição e/ou fragmentação de ações na área; discutir processo de legitimação e legalização dos Projetos Educativos Guarani no Estado (Processos de reconhecimento e autorização para funcionamento junto ao CEE - RJ); Programa de Formação de Educadores/as Indígenas; Programa de Construção Curricular; elaborar projetos para captação de recursos. (NOBRE, 2001, p.9)

Dentre as ações do NEl, destacamos o I Encontro Nacional de Educadores Indígenas Guarani, no ano de 2000. Neste encontro, reuniram-se educadores de

\footnotetext{
8 Projeto de extensão "memória e temporalidade Guarani Mbyá: construção de livro paradidático", Universidade Federal Fluminense, Niterói. 2002.
} 


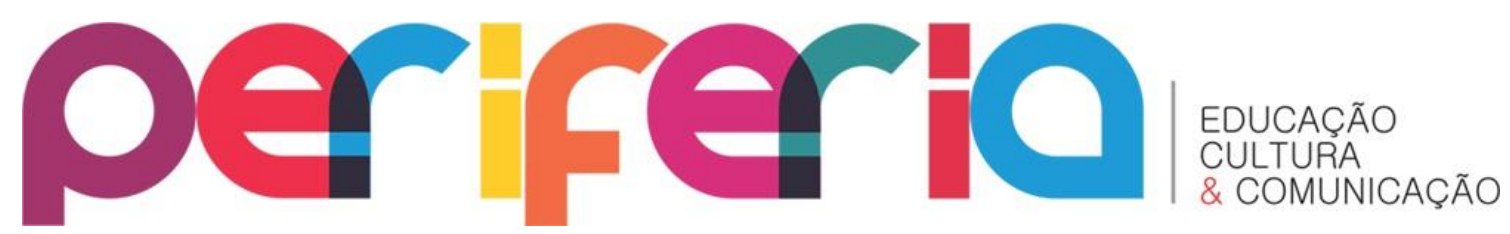

diversas aldeias localizadas em diferentes estados do país, atravessando situações muito diferenciadas de contato com a sociedade envolvida.

O objetivo do encontro foi o de proporcionar um espaço de formação docente e de discussão sobre a formação do professor indígena Guarani, buscando identificar qual o sentido da escola para essas comunidades, constituindo-se em uma iniciativa histórica de política educacional indígena. Dentre as diversas questões que surgiram neste movimento, destacamos aqui algumas falas que ajudam a perceber quais as expectativas e os pressupostos que consolidaram esse movimento no Rio de Janeiro:

O que é uma escola? Por que ter escola guarani? Por que não ter escola? (Grupo Juruá, 2000)

Se só houvesse comunidades indígenas, não haveria motivos para ter escola, pois não sofreriam influências de outras comunidades; hoje não há motivos para não ter escola. (Sérgio, aldeia Itaxi, 2000)

Antigamente, havia ensinamentos orais (na casa de reza), que ensinavam a moral e a cultura. Escola branca não serve, pois destrói a cultura do índio. Não há motivos para não ter escola Guarani, pois ela ajuda a preservar a cultura. (Poty Porã, Aldeia Jaraguá, 2000) ${ }^{9}$.

$\mathrm{Na}$ fala dos professores presentes nesse encontro, há quinze anos, podemos perceber que alguns questionamentos ainda são atuais. Percebe-se, também, que a maioria desses professores continua na militância por uma educação escolar indígena de qualidade, que respeite as formas de ensinar e aprender dos Guarani e que seja gerida por eles.

Percebemos que, na América e em todos os locais que sofreram o processo colonizador, a permanência dos processos de dominação se apresenta na colonialidade do poder, do ser e do saber. O processo de colonização terminou, mas o de colonialidade ainda persiste em nossas formas de organizarmos e distribuirmos o poder, de constituímos o saber e nas formas como nos comportamos e nos

9 Diário de bordo de Norielem de Jesus Martins. 2000. In: MARTINS, Norielem de Jesus. Educação Indígena: A ressignificação da Escola no Contexto Guarani Mbyá no Litoral Sul Fluminense. Monografia de graduação em Pedagogia. Universidade Federal Fluminense. Rio de Janeiro. 2003. 


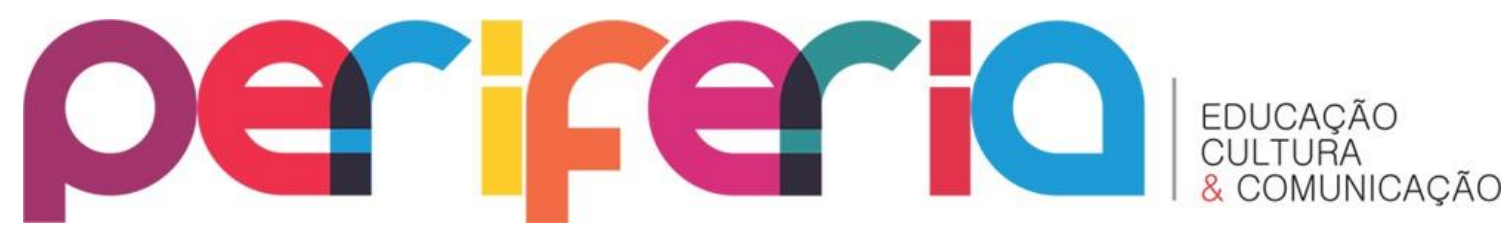

representamos culturalmente. Nelson Maldonado Torres explica o que seria a colonização e a colonialidade, ressaltando que a primeira forma de dominação terminou, mas a segunda continua presente nas nossas vidas:

O colonialismo denota uma relação política e econômica, na qual a soberania de um povo está no poder de outro povo ou nação, o que constitui a referida não em um império. Diferente desta ideia, a colonialidade se refere a um padrão de poder que emergiu como resultado colonialismo moderno, mas em vez de estar limitado a uma relação formal de poder entre dois povos ou nações, se relaciona a forma como o trabalho, o conhecimento, a autoridade a as relações intersubjetivas se articulam entre si através do mercado capitalista mundial e da ideia de raça. Assim, apesar do colonialismo preceder a colonialidade, a colonialidade sobrevive ao colonialismo. Ela se mantém viva em manuais de aprendizagem, nos critérios para o bom trabalho acadêmico, na cultura, no sentido comum, na auto-imagem dos povos, nas aspirações dos sujeitos e em muitos outros aspectos de nossa experiência moderna. Neste sentido, respiramos a colonialidade na modernidade cotidianamente. (TORRES, 2007, p. 131).

Precisamos, portanto, superar o colonialismo. Para fazê-lo, precisamos de um giro decolonial (Castro-Gomez, 2007), um giro na forma como pensamos e organizamos o poder, o conhecimento e a forma como vivemos. A colonialidade subalterniza e invisibiliza a forma como os povos subalternizados pelo colonialismo organizam suas estruturas de poder e produzem seus conhecimentos. As consequências da colonialidade na educação escolar indígena parecem remontar às tentativas de dominação das relações, tanto na produção, quanto na valorização dos conhecimentos, onde o colonizado tenha voz e vez.

Ao falarmos da colonialidade do saber, enquanto um conceito apontado por Quijano (2005), podemos entender o processo de inferiorização e negação do legado cultural dos povos indígenas e africanos no Brasil como um movimento histórico de desvalorização de seus saberes, como se estes fossem menos importantes, menos civilizados, menos rebuscados, mais primitivos e irracionais que os europeus. Dessa maneira, percebemos essa lógica refletida nas escolas, invisibilizando os saberes indígenas, tratados como saberes menores e não científicos. Saberes e histórias muitas 


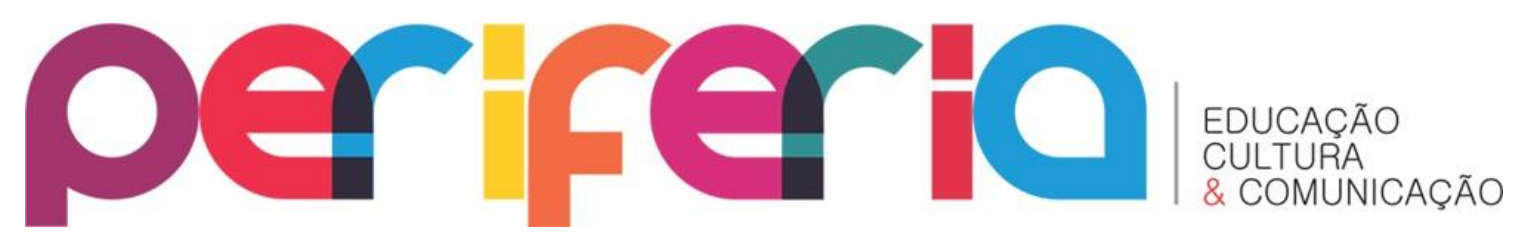

vezes folclorizados e considerados irrelevantes. Esse tipo de pensamento também parece estar presente em muitas escolas indígenas, nas quais a interculturalidade não passa de discurso, uma vez que os manuais didáticos, o currículo, a metodologia e as avaliações seguem as normas e regras das escolas regulares, negligenciando todo um arcabouço de saberes existentes entre os povos indígenas.

Em relação à colonialidade do ser, segundo Walsh (2006), seria uma negação do que somos para "imitarmos" o que se espera de nós, ou como o hemisfério norte nos diz que devemos ser. Sendo assim, tudo que possuímos como elementos identitários que nos caracterizam são negados e inferiorizados, nos induzindo à absorção dos padrões socialmente valorizados, predominantemente ocidentais. Nossa música, nossa língua, nossos cabelos, nossas danças e demais expressões "do sul" tendem a ser vistos como primitivos, exóticos e com menor valor cultural, em detrimento do que se consolidou como o padrão a ser seguido.

Dessa maneira, ao nos apropriarmos de modelos culturais dominantes sem que haja uma contrapartida, ou seja, o conhecimento e a valorização de outras formas de identificação com os saberes - neste caso, indígenas e afro-brasileiros -, somos levados a negar a trajetória dos brasileiros. Pode-se, assim, dar margem aos conflitos étnicos e raciais fundamentados pela ignorância e pela desvalorização de outras formas de saber e viver, o que resulta na violação dos direitos humanos.

Durante muitos séculos, a educação escolar indígena tem resistido a uma proposta integracionista e assimilacionista de uma suposta cultura nacional brasileira. Em 2015, é crescente e notável o protagonismo indígena em muitas áreas do conhecimento, apesar do racismo social predominante e da luta diária pela sobrevivência.

Contudo, apesar de a Constituição de 1988 assegurar aos povos indígenas a utilização de seus métodos próprios de aprendizagem, ainda prevalecem as políticas educacionais integracionistas que desconsideram as especificidades culturais. No Estado do Rio de Janeiro, há quase duas décadas, as reivindicações comunitárias tem sido praticamente as mesmas: contratação de professores, ampliação das escolas, 


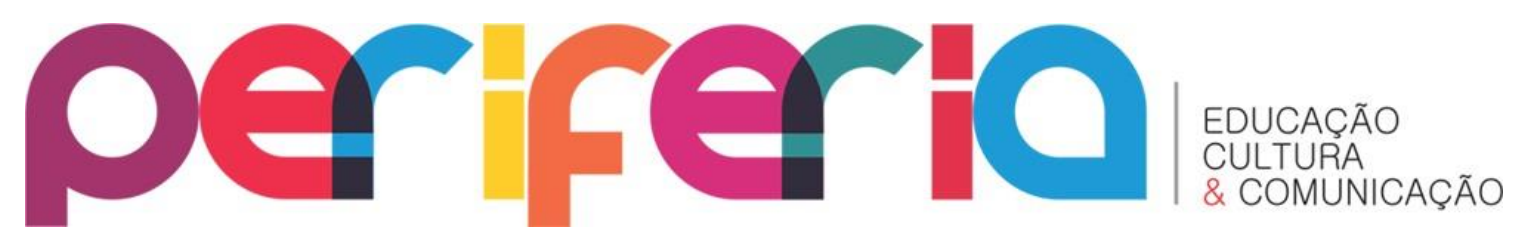

quantidade da merenda escolar, necessidade do magistério indígena, dentre outras. É necessário que se constitua de fato o que é legal e legítimo: uma educação escolar indígena intercultural, diferenciada, específica e bilíngue, de modo que os próprios indígenas possam organizar as escolas em suas comunidades.

Será possível, em algum momento, deixarmos o campo do discurso legítimo para a aplicação real? Embora não tenhamos resposta para este questionamento, consideramos que, para uma proposta de educação escolar intercultural, diferenciada, específica e bilíngue, é necessário estarmos atentos para aplicação de uma pedagogia decolonial, que leve em consideração, como afirma Walsh (2005), "saberes outros". Que se constitua como uma estratégia de decolonização, de transformação e criação, no qual os saberes dos povos indígenas estejam em igualdade com os saberes predominantemente ocidentais. Uma estratégia que reconstrua o ser, o saber e o poder, de forma que os povos indígenas - bem como os povos africanos - sejam respeitados e valorizados.

Nesse sentido, é necessário adotar o que Walsh (2005) chama de posicionamento crítico de fronteira. Esse pensamento não tem como premissa a construção de uma sociedade ideal, mas a transformação da colonialidade do ser, do poder e do saber, tendo consciência de que essas relações não desaparecem, mas, que podem ser reconstruídas, constituindo-se de maneiras diferentes. Nesse caso, outras formas de pensar, de produzir o conhecimento e de ser se tornam visíveis e relevantes. Há um diálogo entre os saberes e o ser, e não uma hierarquização entre eles.

Nesse momento, a interculturalidade torna-se imprescindível como forma de diálogo entre os saberes. Para Walsh, a interculturalidade significa:

- um processo dinâmico e permanente de relação, comunicação e aprendizagem entre culturas em condições de respeito, legitimidade mútua, simetria e igualdade.

- Um intercâmbio que se constrói entre pessoas, conhecimentos, saberes e práticas culturalmente diferentes, buscando desenvolver um novo sentido entre elas na sua diferença. 


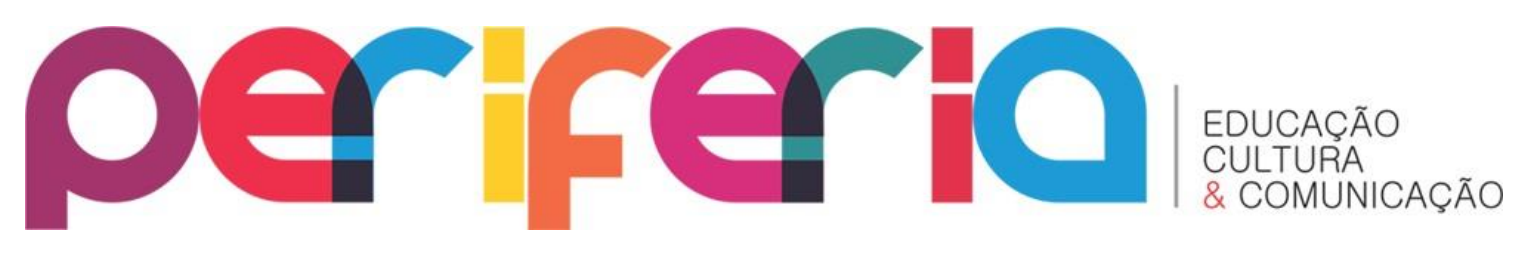

- um espaço de negociação e de tradução onde as desigualdades sociais, econômicas e políticas, e as relações e os conflitos de poder da sociedade não são mantidos ocultos e sim reconhecidos e confrontados.

- Uma tarefa social e política que interpela ao conjunto da sociedade, que parte de práticas e ações sociais concretas e conscientes e tenta criar modos de responsabilidade e solidariedade.

- Uma meta a alcançar. (WALSH, 2001, p. 10-11)

A interculturalidade tem um papel fundamental na construção de uma pedagogia e práticas pedagógicas decoloniais, inserindo no campo do conhecimento escolar os saberes das culturas indígenas. Além disso, com ela pode-se demonstrar que essa hierarquização de conhecimentos de culturas existentes na sociedade, bem como a subalternização desses povos, são reflexos de um processo de dominação, cujo discurso decolonial desnaturaliza.

Meliá (2002) apresenta os conceitos de intraculturalidade e interculturalidade, exemplificados a partir de uma palavra Guarani, o ñande (nós, em português). Para Meliá, na língua Guarani existem sentidos distintos para a palavra nós: um sentido inclusivo "ore", que significa "nós e os outros" e um sentido particular, exclusivo: o "nhande", que significa "apenas entre nós". Utilizando a analogia de Meliá, percebemos que, nesse contexto, a intraculturalidade seria o "apenas entre nós", as comunidades indígenas. E a interculturalidade, seria o "nós e os outros", os não indígenas.

[...] toda cultura se constituye en un nosotros doble, de inclusión y exclusión a la vez. La lengua guaraní, como otras lenguas, ha categorizado gramatical e léxicamente esta duplicidad ontológica del nosotros, que podemos considerar constitutivo de cultura, usando un plural de primera persona inclusivo; nãnde; y otro exclusivo, ore. (MELIÁ, 2002, p.78)

Essa relação entre a "intraculturalidade" e a interculturalidade possibilita ampliar o campo de discussão. Levar tal relação em conta inclui o outro na sociedade atual não como fruto de uma cultura homogênea, mas como sujeito de relações 


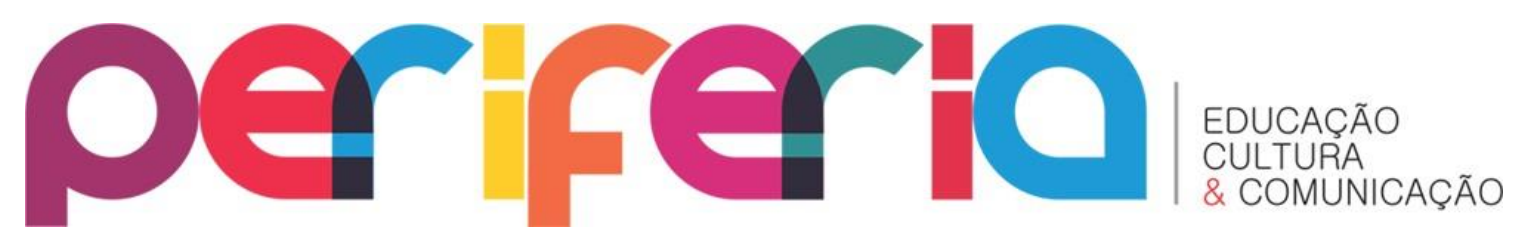

culturais de exclusão e subordinação entre culturas de maior ou menor poder, resistindo, transformando e interagindo com a sociedade.

Em janeiro de 2001, foi lançado o Plano Nacional de Educação, que definiu diversas prioridades para a Educação escolar diferenciada indígena, dentre elas a criação da categoria escola indígena ${ }^{10}$ pelo Governo do Estado, e a responsabilidade deste, junto ao Governo Federal, na manutenção destas escolas.

As escolas diferenciadas Guarani Mbyá no Rio de Janeiro foram reconhecidas pelo Conselho Estadual de Educação, em 22 de abril de 2003, após um trabalho articulado entre os professores indígenas, lideranças das comunidades e assessorias não indígenas. Atualmente as escolas estaduais indígenas do Litoral Sul Fluminense estão interligadas, tendo como escola polo, o Colégio Indígena Estadual Karai Kuery Renda, localizado na Aldeia de Sapukai, e três salas de extensão, nas aldeias de Itaxi, Araponga e Rio Pequeno. As escolas contam com edificações precárias e inapropriadas, carecendo de recursos básicos, como materiais didáticos específicos, professores guarani concursados, conselho escolar indígena, ampliação do espaço físico, entre outros. Também falta a continuidade de formação para os alunos que terminaram o primeiro ciclo do ensino fundamental nas aldeias com menor número de habitantes, como a de Araponga e Rio Pequeno.

Durante o período em que a escola das aldeias ofertava apenas os primeiros anos do ensino fundamental, as demandas de formação de jovens e adultos foram supridas pelo Projeto EJA Guarani da Rede Municipal de Angra dos Reis, no período de 2003 a 2014. Em um primeiro momento (2003-2010), o projeto tinha o objetivo de atender a uma demanda de formação de agentes de saúde indígenas, sendo realizado em uma perspectiva interinstitucional, mais voltada a uma pedagogia de alternância, possibilitando a formação de 35 jovens e adultos das aldeias Parati e Angra dos Reis. Posteriormente (2012 a 2014), o projeto objetivava suprir a demanda do curso de

10 Decreto no 33.033 de 22 de abril de 2003 “cria a categoria de escola indígena no âmbito da educação básica, no sistema estadual de ensino do Estado do Rio de Janeiro". 


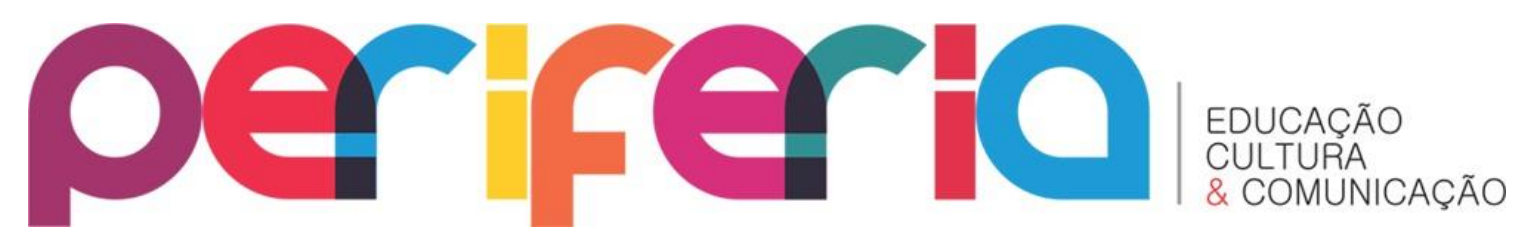

formação em nível médio (magistério indígena), sendo realizado de forma presencial, formando 25 jovens e adultos da aldeia Sapukai em Angra dos Reis.

Até o ano de 2015, o Colégio Estadual era reconhecido apenas como Escola, sendo transformado em Colégio pela resolução SEEDUC RJ no 5227 de 06 de março de 2015. A modificação para categoria de Colégio ocorreu em função da implementação do ensino médio, o que representa um marco legal e uma conquista. Entretanto, desde 2012, a proposta do magistério ainda não saiu do papel. A escola, que então estava autorizada a ofertar apenas o primeiro ciclo do ensino fundamental (1으 ao 5은 ano), tem hoje autorização legal para a oferta, na própria comunidade, de todas as modalidades de ensino pela Secretaria Estadual de Educação (SEEDUC RJ), inclusive da EJA.

A partir dessa transformação, a SEEDUC RJ realizou, no início do período letivo de 2015, um processo de mobilidade interna, que permitiu remanejar professores não indígenas, dentro do quadro permanente da SEEDUC RJ, para atuar nos anos finais do ensino fundamental. Alguns desses professores foram selecionados pela experiência anterior de atuação no projeto EJA Guarani, e os demais professores estão recebendo sua formação inicial específica pela Universidade Federal Fluminense, com o prof. Dr. Domingos Barros Nobre. O objetivo desta formação é, também, construir coletivamente o currículo dos anos finais do ensino fundamental.

Parece que, a partir do ano de 2015, um novo cenário começa a surgir no âmbito da Educação Escolar Indígena no Estado do Rio de Janeiro, embora ainda com passos lentos. Muitos são os desafios entre o legítimo e o real, pois na prática não há professor de língua Guarani atuando nas turmas de anos finais, e não há sequer formação inicial básica em língua guarani para os professores não indígenas, equipe diretiva e coordenação pedagógica. Os entraves burocráticos no âmbito do governo estadual inviabilizam a contratação dos educadores indígenas, não havendo ainda previsão de concurso para estesprofessores. A morosidade na oferta do ensino médio desmobiliza os alunos que já concluíram o ensino fundamental por meio da EJA Guarani. Além disso, ainda existem demandas reprimidas de EJA para anos iniciais e 


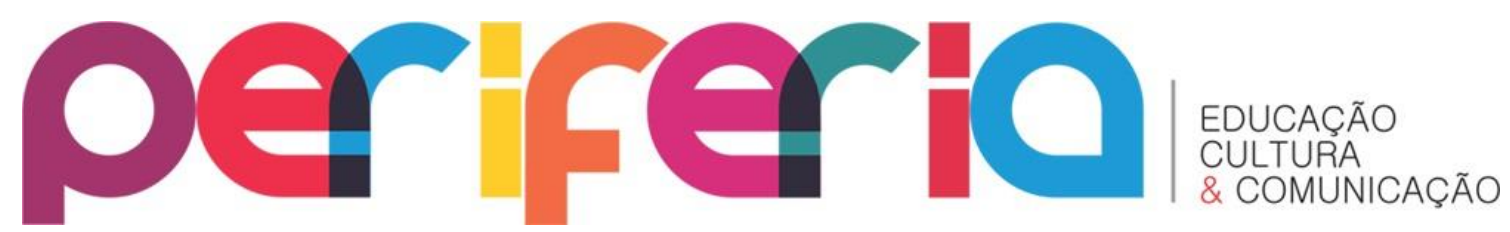

finais do Ensino Fundamental, especialmente em Parati, onde as comunidades não foram atendidas no período de 2012 a 2014.

Para além dos horizontes das escolas, temos um espaço necessário de lutas já instituído e prestes a iniciar seu funcionamento, que é o Conselho Estadual de Educação Escolar Indígena. Paralelo a isso, percebemos que ainda não há articulação necessária entre o Estado e os Municípios no fazer da Educação Escolar Indígena, bem como não há integração, via SEEDUC-RJ, das Aldeias de Maricá nas discussões do Litoral Sul, pois essas pertencem administrativamente a outra Coordenadoria Regional Administrativa. Diante da realidade apresentada, compreendemos que seria essencial, no âmbito da SEEDUC-RJ, um núcleo central e específico de Educação Escolar Indígena para o atendimento de todas as modalidades de forma articulada, em todo o Estado, pois o formato atual dificulta e fragmenta o atendimento das comunidades.

Outra questão essencial que precisa ser discutida e implementada é a composição do conselho escolar indígena nas escolas. Atualmente, a direção e coordenação das escolas é exclusivamente composta por não índios, e a falta dessa participação não garante o fazer diferenciado e legítimo. Por estes e demais fatores, 0 Estado do Rio de Janeiro, com morosos avanços em relação a outros Estados brasileiros, infelizmente, ainda pode ser considerado um dos mais atrasados em relação à educação escolar indígena específica.

Na última Conferência de elaboração do Plano Municipal de Educação de Angra dos Reis, em maio de 2015, foi proposto pelo delegado representante da aldeia Sapukai, professor Algemiro da Silva, a implementação da Educação Infantil nas escolas indígenas. Percebemos que essa é uma demanda motivada por diferentes fatores, que não se resumem apenas à necessidade de uma de educação escolar voltada para as crianças, mas, especialmente, pela falta de articulação entre escola enquanto projeto estatal e as comunidades. Ou seja, como impedir os pequenos de circular no ambiente escolar junto com seus irmãos? Como garantir merenda escolar para todos, diante de um quantitativo limitado de "matriculados"? Outra questão levantada pelo professor Algemiro é que as mulheres da aldeia trabalham, porém 


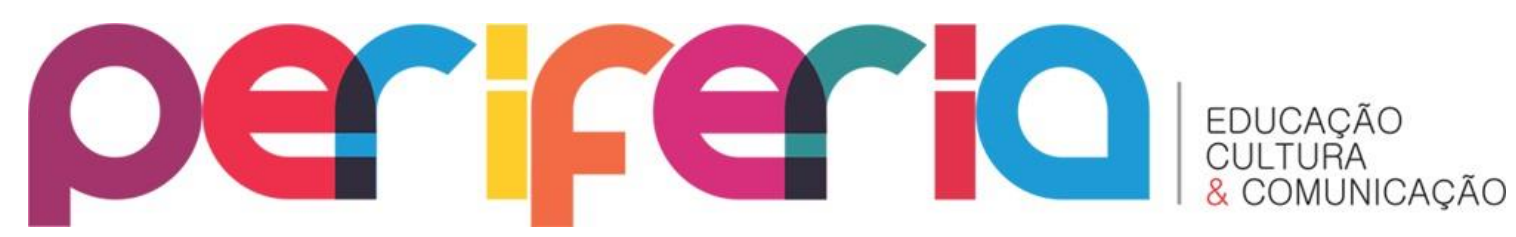

muitas vezes o juruá (não índio) não considera o que elas fazem (se referindo a confecção de artesanatos) como trabalho.

A solicitação do professor Algemiro foi confirmada também na I Conferência de Política Indigenista (etapa local), realizada na aldeia Sapukai em julho de 2015, quando os Guarani de diversas aldeias do Litoral Sul (São Paulo, Espírito Santo e Rio de Janeiro) se reuniram para propor mudanças na política indigenista brasileira. Nessa conferência, foi reafirmado pelos Guarani presentes a proposta de implementação da Educação Infantil nas escolas indígenas como uma necessidade, reforçando as palavras do professor Algemiro sobre o trabalho das mulheres que precisam de um espaço para o cuidado adequado de suas crianças, ressaltando, ainda, a importância de que essa modalidade seja discutida pela comunidade e garantida de maneira específica e diferenciada, não seguindo necessariamente os padrões idade/ ciclo da educação infantil regular.

Esperamos que, a partir da efetivação do curso de magistério indígena, o Governo do Estado do Rio de Janeiro encontre subsídios para ampliar o projeto educacional nas aldeias através da criação de concursos específicos para professores indígenas. Isso deve ser feito mantendo o diálogo com estas comunidades, atentando para a possibilidade de formação destes educadores em diferentes áreas do conhecimento, que atuem em todas as etapas de formação em suas escolas. Consideramos importante, também, a articulação das Universidades com a SEEDUC-RJ e com os Municípios, para que outras habilitações além do magistério possam ser ofertadas a nível médio nas aldeias, de acordo com a realidade/ necessidade local.

\section{CONSIDERAÇÕES FINAIS}

Além de trazer à tona esse período de lutas no campo educacional, buscamos, com esta abordagem teórica, colaborar para que outras percepções acerca da educação escolar indígena no Rio de Janeiro possam emergir, preferencialmente protagonizada pelos próprios indígenas. A educação escolar é uma prática apropriada pela maioria das culturas, porém, quando assumimos um único modelo de escola, 


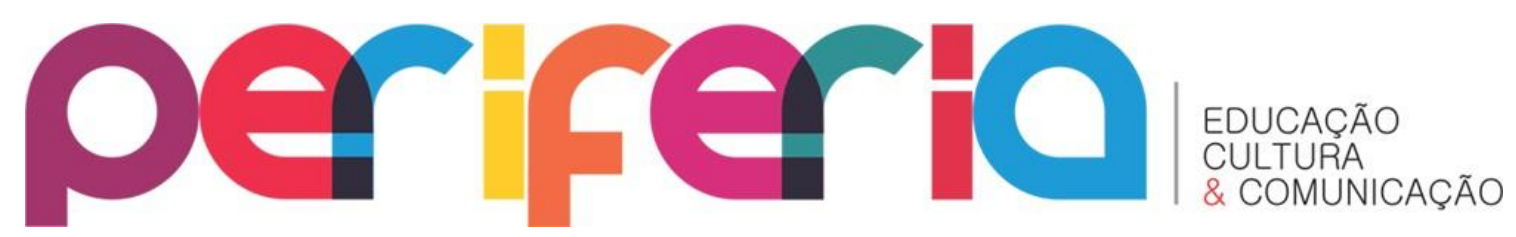

pautado na perspectiva do colonizador, negligenciamos as formas de aprender e ensinar dos diferentes povos que participaram e participam da formação do povo brasileiro, em especial as matrizes indígenas e africanas na educação.

Respeitar outras formas de entender, construir e produzir a existência é fundamental para que possamos construir um mundo onde caibam vários saberes, no qual o respeito à diversidade deixe de ser retórica para se transformar em prática.

Os povos indígenas levaram muitos séculos numa condição de subalternidade de ser, saber e poder. Portanto, faz-se urgente investir em projetos, práticas e movimentos que rompam com essa lógica e trabalhem no caminho emancipador.

Esperamos que esse breve artigo tenha atingido seu objetivo acadêmico e político. Acadêmico ao apresentar a um panorama histórico da educação escolar indígena dos Guarani Mbya do Rio de Janeiro, e político no sentido de denunciar como esse processo de garantia de direitos legitimados desde a constituição brasileira, datada de 1988, tem sido lento, com muitos avanços e recuos. Afinal, somente após uma década os Guarani Mbya das aldeias de Sapukai e Itaxi conseguiram a implantação dos anos finais ensino fundamental em suas aldeias, e as outras modalidades de ensino ainda aguardam implementação. E as outras aldeias, com menor número de habitantes? Quando essas comunidades serão contempladas? Quando conseguiremos romper com a lógica imediatista das gestões que perpassam o poder público, a fim de planejar ações permanentes para a autonomia desses povos? Continuamos aguardando e lutando para garantir que o direito legítimo a uma escola indígena diferenciada, específica, intercultural e bilíngue se torne real.

\section{REFERÊNCIAS BIBLIOGRÁFICAS}

BARROS, Armando Martins de. Educação, interculturalidade e democracia: a escola diferenciada indígena e a formação dos professores Guaranis no Rio de Janeiro. Revista Teias, Rio de Janeiro: UERJ - Faculdade de Educação, 2ำ sem., 2001a.

BARROS, Armando Martins de; CASTRO, Renata Pinheiro (Org.) Ara reko: Memória e Temporalidade Guarani. 2a Ed. E-Papers. Rio de Janeiro:2005. 


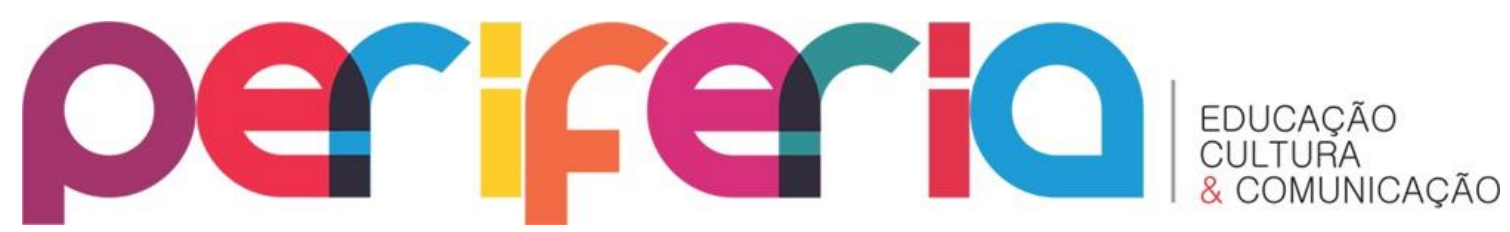

BARROS, Armando Martins de; LIMA, Waysa. Temporalidade e memória indígena: desafios gnoseológicos na formação de professores Guaranis para escola diferenciada. Revista Tellus/ NEPPI, ano 2, n. 3. Out. 2002. Campo Grande/ MS: UCDB, 2002.

BRASIL. Lei de Diretrizes e Bases da Educação Nacional. LDB. 1998

CLASTRES, Hélène. Capítulo V: Justiça do Homem. A terra sem Mal. O profetismo TupiGuarani. São Paulo: Brasiliense, 1978.p 92-108.

COHN, Clarisse. Educação Escolar Indígena: Para uma discussão de cultura, criança e cidadania ativa. Perspectiva, Florianópolis, v.23, n2, p.485-515. Jul/ Dez. 2005

COLLET, Celia Leticia Gouvea. Interculturalidade e Educação escolar indígena: Um breve histórico. Cadernos de Educação Indígena. Barra do Bugres: UNEMAT, v.2, nำ1, 2003.

D'ANGELIS, Wilmar da Rocha. Leitura e Escrita em escolas indígenas. Juracilda Veiga (Org). Campinas. ALB/ Mercado de Letras: 1997.

DA MATTA, Roberto. O ofício de Etnólogo, ou como ter "Anthropological Blues". In: NUNES, Edson de Oliveira (org). A aventura Sociológica: objetividade, paixão, improviso e método na pesquisa social. Rio de Janeiro: Zahar Editores, 1978.

Antropologia e história. In: Relativizando: uma introdução à antropologia social. Rio de Janeiro. Ed. Rocco, 1987, p.86-133.

FREIRE, José Ribamar Bessa; MALHEIROS, Márcia Fernanda. Aldeamentos indígenas no Rio de Janeiro. 2 $\stackrel{a}{a}$ edição. Rio de Janeiro: EDUERJ, 2010.

Fontes históricas para a avaliação da escola indígena no Brasil. Revista Tellus/ NEPPI, ano 2, n. 3. Out. 2002. Campo Grande/ MS: UCDB, 2002.

- Cinco ideias equivocadas sobre o índio. Revista do Centro de Estudos do Comportamento Humano (CENESCH). № 01 - Setembro 2000. P.17-33.

GRUPIONI, Luís Donisete Benzi. As Leis e a Educação escolar Indígena. Programa Parâmetros em Ação de Educação Escolar Indígena- Brasília: Ministério da Educação, Secretaria de Educação Fundamental. 2001.

LUCIANO, Gersem dos Santos. O Índio Brasileiro: o que você precisa saber sobre os povos indígenas no Brasil de hoje - Brasília: Ministério da Educação, Secretaria de Educação Continuada, Alfabetização e Diversidade; LACED/Museu Nacional, 2006.

MALDONADO-TORRES, Nelson. Sobre la colonialidad del ser: contribuciones al desarrollo de un concepto. In: CASTRO-GÓMEZ, S.; GROSFOGUEL, R. (Orgs.) El giro decolonial. Reflexiones para una diversidad epistémica más allá del capitalismo global. Bogotá: Universidad Javeriana-Instituto Pensar, Universidad Central-IESCO, Siglo del Hombre Editores, 2007. p. 127-167.

MARTINS, Norielem de Jesus. Educação Indígena: A ressignificação da Escola no Contexto Guarani Mbyá no Litoral Sul Fluminense. Monografia de graduação em Pedagogia. Universidade Federal Fluminense. Rio de Janeiro. 2003. 


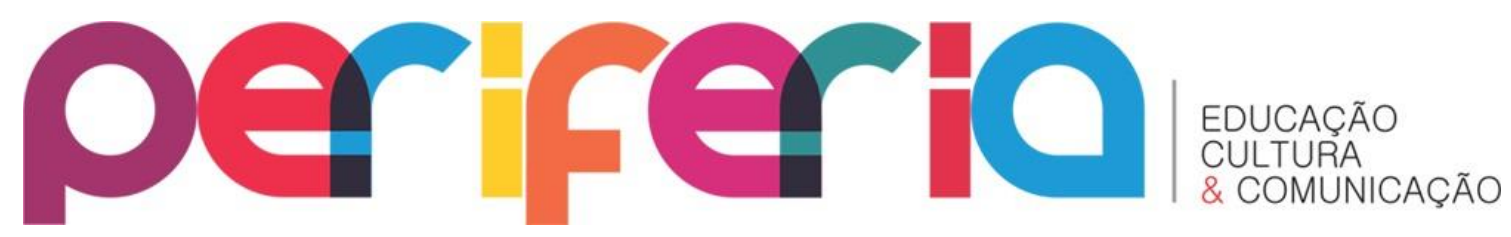

- Trajetórias da Educação Escolar Indígena no Rio de Janeiro - A ressignificação da escola pelos guarani mbyá. Monografia de especialização. Universidade Federal Fluminense. Rio de Janeiro. 2012.

MIGNOLO, Walter. Histórias Globais/projetos Locais. Colonialidade, saberes subalternos e pensamento liminar. Belo Horizonte: Editora UFMG, 2003.

- A colonialidade de cabo a rabo: o hemisfério ocidental no horizonte conceitual da modernidade. In: LANDER, E. (Org.). A colonialidade do saber: eurocentrismo e ciências sociais. Perspectivas latino-americanas. Buenos Aires: Clacso, 2005. p. 71-103.

MEC. Referencial Curricular Nacional para Escolas Indígenas - RCNEI. Ministério da Educação. Secretaria de Educação Fundamental. MEC/ SEF: Brasília: 1998.

MELIÀ, Bartolomeu. Educação indígena e alfabetização. Edições Loyola. SP. 1979.

. Elogio de la Lengua Guarani. Educação indígena e Escola. CEPAG. Paraguai. 1995. Trad. Wilmar R. D'Angelis - (para uso em encontro nacional de professores Guarani/ Angra dos Reis, 28/02 a 06/03/2000).

. Diversidade cultural e educação intercultural. Revista Tellus/NEPPI, ano 2, $\mathrm{n}$.

3. Out. 2002. Campo Grande/ MS: UCDB, 2002.

MONSERRAT, Ruth Maria Fonini. Para um autêntico bilingüismo. In: Por uma educação indígena diferenciada. Brasília: Projeto interação. C.N.R.C; FNPM, 1987.

MONTE, Nietta L. Escolas da Floresta: entre o passado oral e o presente letrado; diários de classe de professores Kaxinawá. Rio de Janeiro: Multiletra, 1996.

NOBRE, Domingos Barros. Processos de Construção de Políticas em Educação Escolar Indígena no Estado do Rio de Janeiro.24a Reunião Anual da ANPEd, 2001.

OLIVEIRA, Luiz Fernandes de, CANDAU, Vera Maria. Pedagogia decolonial e educação antirracista e intercultural no Brasil. Educação em Revista. vol.26, $\mathrm{n}^{\circ} .1$ Belo Horizonte: abril, 2010.

ORLANDI, Eni Pulcinelli. Algumas considerações discursivas sobre a Educação Indígena. Em aberto. Brasília, ano 3. no 21. abr/jun. 1984.

PALADINO, Mariana. Educação escolar Indígena no Brasil Contemporâneo: Entre a "Revitalização Cultural" e a "Desintegração do Modo de Ser Tradicional". Dissertação de Mestrado. Programa de Pós-Graduação em Antropologia Social - Museu Nacional UFRJ. Rio de Janeiro. 2001

PALADINO, Mariana; CZARNY, Gabriela. "Interculturalidade, conhecimento Indígena e Escolarização". In: Povos indígenas e escolarização. Discussões para repensar novas epistemes nas sociedades latino-americanas. Rio de Janeiro: Editora Garamond. 2012 (no prelo). 


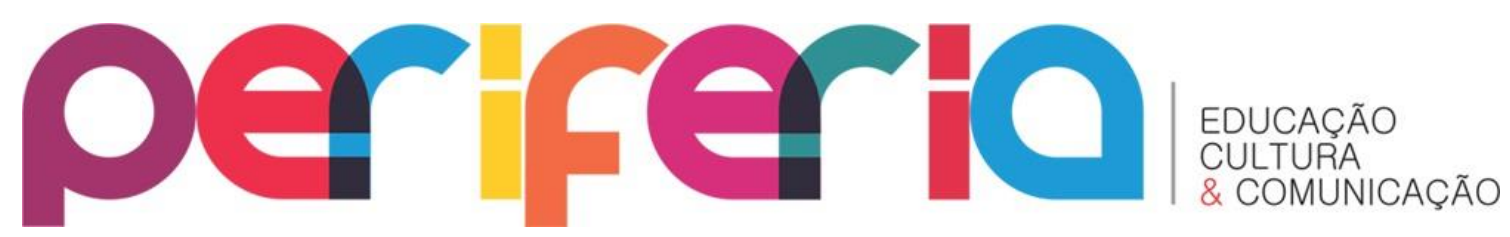

PISSOLATO, Elizabeth de Paula. A Duração da Pessoa: mobilidade, parentesco e xamanismo mbya (guarani). Rio de Janeiro: UFRJ/MN/PPGAS, 2006.

QUIJANO, Aníbal. Colonialidad del poder, eurocentrismo y América Latina. In: LANDER, E. (Org.). La colonialidad del saber: eurocentrismo y ciencias sociales. Perspectivas Latinoamericanas. Buenos Aires: Clacso, 2005. p. 227-277

QUIJANO, Aníbal. Colonialidad del poder y clasificación social. In: CASTRO-GÓMEZ, S.; GROSFOGUEL, R. (Orgs.). El giro decolonial. Reflexiones para una diversidad epistémica más allá del capitalismo global. Bogotá: Universidad Javeriana-Instituto Pensar, Universidad Central-IESCO, Siglo del Hombre Editores, 2007. p. 93-126.

SANTOS, Boaventura de Sousa; Meneses, Maria Paula (org). Epistemologias do Sul. Coimbra: Edições Almedina. 2009.

SOUZA, Luiz Antônio Catafesto; BONIN, lara Tatiana. Crianças Mbyá. Notas sobre espaços e tempos educativos. IX Reunião de Antropologia do Mercosul. 2011 - Curitiba, PR.

WALSH, Catherine. La educación Intercultural en la Educación. Peru: Ministerio de Educación. (documento de trabalho), 2001

WALSH, Catherine. Introducion - (Re) pensamiento crítico y (de) colonialidad. In: WALSH, C. Pensamiento crítico y matriz (de) colonial. Reflexiones latinoamericanas. Quito: Ediciones Abya-yala, 2005. p. 13-35

WALSH, Catherine. Interculturalidad y colonialidad del poder. Un pensamiento y posicionamiento 'otro' desde la diferencia colonial". In: WALSH, C.; LINERA, A. G.; MIGNOLO, W. Interculturalidad, descolonización del estado y del conocimiento. Buenos Aires: Del Signo, 2006. p. 21-70. 